\title{
Transitioning to College: Experiences of Successful First-Generation College Students
}

\author{
Jonathan R. Ricks, PhD \\ University of North Carolina at Pembroke, Pembroke, North Carolina, United States \\ Jeffrey M. Warren, $\mathrm{PhD}$ \\ North Carolina Central University, Durham, North Carolina, United States \\ Contact: jonathan.ricks@uncp.edu
}

\section{Abstract}

This qualitative study explored the high school to college transition experiences of ten successful firstgeneration college students (FGCS). Participants were college seniors at an historically black university in the United States. A generic qualitative research design was used, including in-depth, semi-structured interviews to collect and analyze data. Participants reported that the transition experience led to confusion with academic and financial procedures, various emotions including anxiety and fear, the realization that they had deficits in academic skills, and the receipt of support from family members and others. Cultural and social capital appeared to play key roles in their success. Student affairs professionals are encouraged to explore targeted, individualized strategies that meet the needs of FGCS as they transition to college.

Keywords: first-generation college students; transition; cultural capital; social capital; student affairs

Date Submitted: November 18, 2018 | Date Published: February 19, 2021

\section{Recommended Citation}

Ricks, J. R., \& Warren, J. M. (2021). Transitioning to college: Experiences of successful first-generation college students. Journal of Educational Research and Practice, 11, 1-15. https://doi.org/10.5590/JERAP.2021.11.1.01

\section{Introduction}

First-generation college students (FGCS) are students whose parents did not attend college or earn a college degree (Redford \& Mulvaney Hoyer, 2017). These students comprise one-third of all college students; only 27\% earn degrees within four years (Whitley et al., 2018). After six years, 65\% of FGCS are still enrolled or have earned a degree compared to $73 \%$ and $83 \%$ for their peers whose parents either completed some college or earned a bachelor's degree, respectively (Forrest Cataldi et al., 2018).

Researchers have suggested that FGCS possess limited knowledge of the college student role and college culture and generally complete fewer credit hours during the first year of college when compared to continuing-generation college students (CGCS), students whose parents attended college and earned a degree (Ardoin, 2018; Garrison \& Gardner, 2012; Pascarella et al., 2004; Zeisman, 2012). According to Atherton (2014), FGCS participate less in studying and extracurricular activities and generally received lower grade point averages in the first year of college. Additionally, FGCS have reported the need to work during college and are required to complete more developmental coursework (Davis, 2010). As a result of these obstacles,

Note: Jonathan R. Ricks, PhD, is an assistant professor in the Department of Counseling at the University of North Carolina at Pembroke. 
Ricks \& Warren, 2021

first to second-year attrition rates for FGCS have been as high as 50\% (Garrison \& Gardner, 2012; Pascarella et al., 2004; Zeisman, 2012). After three years of college, only $48 \%$ of FGCS persist compared to $53 \%$ for students whose parents attended some college and $67 \%$ for students whose parents completed a bachelor's degree (Forrest Cataldi et al., 2018).

While most FGCS fail to earn a college degree, a small percentage successfully transition from high school to college and persist toward graduation. Few studies, however, have investigated the lived experiences of successful FGCS. This study explores the transition experiences of FGCS and offers secondary school college access professionals, school counselors, student affairs professionals, and college educators recommendations for preparing and supporting this college student population.

\section{First-Generation College Students}

FGCS often are at a distinct disadvantage "when it comes to postsecondary access-a disadvantage that persists even after controlling for other factors such as educational expectations, academic preparation, support from parents and schools in planning and preparing for college, and family income" (Choy, 2001, p. 4). FGCS often perceive college education as a requirement to successful employment; they often attend colleges that are close to home regardless of the fit and, as a result, fail to complete degree requirements (Choy, 2001; Horn \& Nevill, 2006, Warren et al., 2020). Furthermore, FGCS are more likely to live at home and work part-time and also experience lower self-esteem and struggle with social acceptance, as compared to CGCS (Falcon, 2015; Horn \& Nevill, 2006). However, FGCS are more likely to attend low-quality high schools that do not provide the rigorous academic curriculum needed for college-level coursework (Atherton, 2014; Bui, 2002; Ardoin, 2018).

Bourdieu (1977) suggested these challenges are explained through the theory of cultural and social capital. "Cultural capital" is described as the ability to communicate effectively, knowledge of the educational system, and an understanding of educational pathways. Cultural capital is acquired over time through the home and parental socialization. Students with cultural capital are more likely to go to college and obtain a prestigious career (Ardoin, 2018). FGCS often have families without institutionalized cultural capital, or knowledge of college degrees and credentials, and therefore lack the experience of college selection and the application process (Ardoin, 2018; Wimberly \& Noeth, 2004). As a result, FGCS lack knowledge about the general college experiences and don't understand how to navigate university systems (Garriott \& Nisle, 2017; Pascarella et al., 2004).

"Social capital" is defined as the value of a relationship that provides support and assistance in certain social situations (Bourdieu, 1977; Stanton-Salazar, 2001). Social capital is dependent upon students' socioeconomic status and parental education (Ardoin, 2018; Pascarella et al., 2004; Stanton-Salazar, 2001). FGCS typically interact in socially and academically different ways in the college setting (Means \& Pyne, 2017). They study less, earn lower grades, and take fewer courses in humanities, arts, and natural sciences (Pascarella et al., 2004). FGCS also are less involved in extracurricular activities such as clubs and student organizations, less likely to get to know their professors, and hesitant about interacting with their peers in non-academic settings (Pascarella et al., 2004; Pike \& Kuh, 2005).

A lack of involvement in college is especially harmful for FGCS (Baxter Magolda, 1992; Inman \& Pascarella, 1998; Whitt et al., 2001). Demetriou et al. (2017) and Means and Pyne (2017) found that engagement in extracurricular activities and connections with peers benefit FGCS more than CGCS. Engagement leads to greater gains in critical thinking, writing skills, reasoning, and plans for higher education (Pascarella et al., 2004). FGCS benefit from participation in extracurricular activities and social interactions with CGCS (Demetriou et al., 2017). This form of social capital has been found to improve students' motivation, degree plans, intellectual development, and personal growth (Pascarella et al., 2004). Differences in the quality and quantity of social networks that students can access may explain differences in academic engagement and persistence in college (Demetriou et al., 2017; Frazier, 2020; Stanton-Salazar, 1997). 
Ricks \& Warren, 2021

CGCS have a much easier path toward postsecondary education and degree attainment (Forrest Cataldi et al., 2018) and often possess the cultural and social capital described by Bourdieu (1977). Alternatively, FGCS often have deficits in cultural (Dumais \& Ward, 2010) and social (McDonough, 1997) capital, key obstacles to college. According to Bourdieu (1977, 1992), many first-generation students will opt out of pursuing a college degree because they feel that it is not for them and they do not have the same sense of entitlement or belonging as their continuing-generation counterparts.

While many FGCS are unsuccessful in their efforts to complete college (Whitley et al., 2018; Forrest Cataldi et al., 2018), some do persist and graduate with a degree. Garrison and Gardner (2012) identified several strengths of FGCS that are directly connected to learning and persistence. FGCS were motivated, resourceful, and repeatedly sought support from adults to help them navigate personal, social, and academic dilemmas (Garrison \& Gardner, 2012). Additionally, they demonstrated the ability to strategically research and evaluate information and participated in effective decision-making to meet academic requirements.

According to Whitley et al. (2018), FGCS have a "track record of beating the odds" (p. 26). Educators described them as ambitious and motivated to achieve educational endeavors that family members thought impossible. FGCS also have demonstrated unrelenting efforts toward personal and academic accomplishments, oftentimes overcoming several obstacles (Garrison \& Gardner, 2012; Thrasher, 2016; Whitley et al., 2018). In this study, we aimed to build from this work by exploring the role cultural and social capital plays in successful FGCS transition. The research question in this study is, "what are the experiences of first-generation college students during the transition to college and how did these experiences lead to success?”

\section{Method}

\section{Research Design}

We used a generic qualitative research design in this study because it is discovery-oriented and seeks to uncover the meaning of participant experiences (Creswell \& Poth, 2017). Miles et al. (2014) asserted that phenomenology emphasizes a person's construction of their everyday life and their world. Employing this approach allowed us to uncover trends in thoughts and consciousness, which afforded us the opportunity to explore the lived experiences of successful FGCS in a deep and meaningful way (Creswell \& Poth, 2017). A major goal of qualitative research is to examine a participant's intentionality, or internal experience of being conscious of something (Hays \& Singh, 2012).

\section{Participants}

This investigation explored the lived experiences of ten FGCS in their senior year of college at a public, historically Black university in the southeastern United States. Participants were deemed successful FGCS because they met the following criteria: (a) met the definition of a FGCS, (b) currently had an above-average cumulative grade point average (equal to or greater than 3.0), and (c) were classified as a college senior. All participants had persisted in college and were within one semester of earning a bachelor's degree on the date of the interview. Most participants were Black, female, and all were on track to complete their degree within four years. Descriptive data for each participant in this study is presented in Table 1. Each participant selected a pseudonym to use as their name in the study to protect their confidentiality. 
Table 1: Demographics of First-Generation College Student Participants

\begin{tabular}{llllll}
\hline Pseudonym & Gender & \multicolumn{1}{c}{ Ethnicity } & Age & $\begin{array}{c}\text { Current } \\
\text { GPA }\end{array}$ & \multicolumn{1}{c}{ Major } \\
\hline Courtney & F & Black & 22 & 3.15 & Social Work \\
Gabrielle & F & $\begin{array}{l}\text { Multi-racial (White and } \\
\text { Black) }\end{array}$ & 22 & 3.9 & Criminal Justice \\
Jayla & F & Black & 21 & 3.6 & Psychology \\
Josh & M & Black & 21 & 3.1 & $\begin{array}{l}\text { Mass } \\
\text { Joy }\end{array}$ \\
Leata & F & Black & & & Communications \\
Mare & F & Black & 21 & 3.4 & Social Work \\
Monique & F & White & 21 & 3.0 & Social Work \\
Rashed & B & Black & 24 & 3.0 & Biology \\
Tracy & F & Black & 21 & 3.5 & Psychology \\
& & & 21 & 3.2 & Political Science \\
& & & 20 & 3.7 & Biology, \\
& & & & Pre-Medicine \\
\hline
\end{tabular}

\section{Procedures}

A research protocol was developed after soliciting input from two college-student-support professionals that work primarily with FGCS. The interview questions were then reviewed by three faculty members in a college of education: two doctorate-level counselor educators and one doctorate-level qualitative methods expert. After we revised the protocol based on feedback received, the university's Institutional Review Board (IRB) reviewed and approved the interview questions. Once the protocol was approved, an email soliciting participation was forwarded to the university registrar for dissemination to all students who met eligibility criteria. Students were instructed to contact the lead researcher via email if they were interested in participating in the study and met the outlined criteria. The interviews were scheduled on a day and time convenient for each participant over the course of several weeks. All interviews were conducted in person in an office on campus.

Prior to beginning each interview, we shared an overview of the study and provided a copy of the informed consent form to ensure that all students were fully aware of their role in the study as a participant. Once consent was obtained, the interview was conducted and recorded with a digital audio recording device that lacked internet connectivity. Audio data were captured from each participant to enhance the data analysis phase of this study. Interviews ranged in length from 31 minutes to 64 minutes; the average length was 44 minutes. During and after each interview, the lead researcher recorded written memos to describe findings as they developed. Writing initial thoughts about a research experience and participant responses in the research notes is an important part of data collection (Hays \& Singh, 2012). The research team used memos in combination with other data during the data analysis phase of the study. 
Ricks \& Warren, 2021

\section{Research Team}

Data collection was completed by the lead researcher, a White male and 37-years old at the time of the study; he also once was a FGCS. He was employed as a school counselor for seven years and also worked for three and a half years as an academic advisor at a public university. In his role as academic advisor, he supported FGCS during their first 2 years of college.

The coding team included the lead researcher and two counselor educators with earned doctoral degrees in counselor education and supervision; both identified as White and female. All members of the research team had successfully completed coursework in qualitative research methods.

\section{Trustworthiness}

In qualitative investigation, researchers are encouraged to establish trustworthiness and engage in strategies that are appropriate for the research tradition guiding the study (Hays \& Singh, 2012). These strategies demonstrate a good faith effort by the researcher to conduct all aspects of the study with fidelity and objectivity (Creswell \& Poth, 2017). In the current study, several strategies were employed to demonstrate trustworthiness of the research process, data interpretation, and results. The researcher and data collector bracketed his experiences and beliefs throughout the study by keeping a personal reflexive journal (Hays \& Singh, 2012). The journal provided a space for the researcher to document his assumptions and personal feelings, constantly reflecting throughout the research process in order to report the data accurately. Bracketing affords researchers the opportunity to increase awareness of subjectivity and preconceived thoughts about the participant group that may influence aspects of the study (Creswell \& Poth, 2017). The lead researcher utilized field notes and memos as well as persistent observation to focus on and document the characteristics of the population under investigation. Additionally, we gathered thick descriptions of participant experiences and completed transcript checking with participants to verify the accuracy of the transcripts and triangulation of research methods to achieve trustworthiness. All of these strategies are appropriate for qualitative studies (Hays \& Singh, 2012).

\section{Data Collection}

A demographic questionnaire was used to capture the age, gender, race/ethnicity, and cumulative grade point average of each participant. Additionally, we used semi-structured, open-ended interviews in order to better understand the phenomena under investigation, high school to college transition experiences of successful FGCS. The interview consisted of a request to provide background information and five open-ended questions or prompts. Examples include "Describe your experience of transitioning from high school to college" and "When you first came to college, what questions or concerns, if any, did you have about processes and procedures?” A semi-structured, in-depth interview protocol allowed participants the opportunity to share a rich description of their experiences while guiding the structure and process of the interview (Creswell \& Poth, 2017).

\section{Data Analysis}

The lead researcher transcribed verbatim the audio data collected during the semi-structured interviews using a word processor. Once all data were transcribed, a member check was conducted; each participant received an electronic transcript of their interview to review for accuracy and completeness. The lead researcher received feedback from participants based on the reviewed transcripts and addressed any discrepancies and added additional information. Once all cases or transcribed interviews were complete, the team began analysis of the data.

Initially, the research team independently developed a list of significant or meaningful statements from the 
participants' transcripts. Each statement identified was equally weighted, evaluated, and considered during the development of a list of non-repetitive and non-overlapping statements. After reviewing each members' list of statements, the team compiled a master list through a group consensus process. Additionally, we engaged in data reduction and elimination, which helped to ensure that each statement was applicable to the phenomena under investigation (Creswell \& Poth, 2017). Then, the research team engaged in open-coding procedures to group the statements into themes, or broader blocks of similar information. Coded statements were then analyzed by the research team to determine patterns of participant experiences (Miles et al., 2014). Finally, the research team negotiated the emerging themes and consensually agreed on major themes and associated coded statements. The findings from the analysis are included in this study.

\section{Findings}

Four major themes emerged from the data collected based on the responses of the participants' lived experiences related to their transition from high school to college. The themes included: (a) questions and confusion during the first year of college, (b) personal and social experiences, (c) academic-related transition experiences, and (d) support provided during the transition experience.

\section{Questions and Confusion During the First Year of College}

Several participants described experiencing confusion about policy and procedures when first entering college. Participants reported that they attended and participated in summer orientation; however, group advising was complicated and they did not have ample time to ask questions. As a result, most concerns centered around academic-related matters, financial aid and housing procedures, and personal and social questions. Several students recalled having specific questions about academic policies, resources, class supplies, and degree requirements. Two participants recall confusion about which textbooks to purchase for classes. Josh explained being confused about academic procedures and the use of technology:

Freshman year definitely wasn't easy. When I first got to college I didn't check my email. I knew nothing about Blackboard [learning management system] and going on the websites and looking for work online was hard. I also didn't know anything about syllabi. It was very different from high school.

The participants also were unclear about course registration and how to develop a course plan to ensure ontime graduation. They felt pressure to earn a certain number of credit hours during their first year in order to classify as a sophomore; however, the exact number of credits needed was not known. Josh further explained:

I was trying to graduate on time. I needed to know exactly what to take and when to take it. A lot of people won't tell you the truth. People will just steer you all in wrong directions to get you to take stuff just because.

Financial aid procedures were particularly confusing to many of the participants in this study. Among financial aid questions, the participants described having questions about student loans and financial support. The students were asked for tax forms and transcripts, yet had to explain that their parents did not have this information readily available. Almost half of the students were dropped from their courses due to unsettled financial aid requirements. Students described a feeling of helplessness in knowing how to complete the requirements for financial support.

Jayla experienced a very difficult time with financial aid:

Financial Aid. Oh my god. It's terrible. It's the devil! I didn't know anything about it. They were saying something about taxes. I didn't know anything about that and I called my mom and she didn't know. 
So the first 2 weeks of school, I didn't have classes because I didn't have financial aid. They were about to take my housing, and everything and my Community Director [University Housing Employee] helped me. My mom came down that day and we got everything situated and it was good to go, but it was really confusing.

Three participants recalled having questions about non-academic and non-financial issues during the first year of college. These questions dealt with making friends, accessing campus life, and general guidance on the new stage in life. For example, Courtney stated, "I think my biggest questions were more personal like how [to] make friends and who I was going to hang out with.” In his discussion about first-year questions, Josh shared, "I wondered what about campus life and different organizations on campus. I didn't know how to go about talking to people or what to talk about to people in the residential life." When pondering questions or concerns during her first year, Jayla described the need for guidance:

My freshman year, I did some things I will regret forever. I was like, "Oh yeah let's do it, everybody's doing it." "Well if everybody did it, then it must not be bad." I wish I had someone to give me guidance during that time.

The participants reflected on their experiences and recognized their need for additional support through the college transition experience.

\section{Personal and Social Experiences}

In addition to academic transition concerns, the participants described personal and social adjustment issues related to the transition to college. Several emotions emerged during the transition-participants felt fearful, lonely, anxious, grief-stricken, and homesick; they also had a sense of renewal. Seven of the 10 participants in this study described feeling lonely, sad, or depressed as they navigated their initial years in college. Jayla described her discomfort of moving to college:

Coming here I felt like nobody wants to meet me and nobody knows who I am. I was sad. I cried every day. Every day. It's really sort of sad to talk about. Because it's like I'm a wimp. Oh it was terrible and I was scared.

While several of the FGCS described challenging emotional experiences during their transition to college, many students also described this as an exciting time for them. Several participants described an insightful, positive personal experience of postsecondary transition. For example, Tracy felt like going to college gave her the chance to start over. She said, "It [the transition] was difficult, but refreshing just because I didn't have to deal with my home situation. It was exciting. I think because it's like a new start, so you get to reestablish yourself." Rashed described moving to college as an empowering experience; he equated college to maturing:

I was happy to be moving from home just for the simple fact that I'd be on my own. I got to prove I can manage myself and I didn't need anyone looking over my shoulder. And that was a key part of growing up because it's like nobody's watching your back, only you're watching your back.

Many participants shared personal characteristics they believed helped them through the transition, including a strong will and determination. Gabrielle shared that personal determination guided her through the uncertain period of transition to college. She describes her reason for persisting:

I was my siblings' first example of somebody who can do it [complete college] without their parents, and I needed to make it look flawless and doable. I couldn't just give up and not being comfortable at first was not a good reason to give up.

Participants were motivated to successfully transition to college and prove to themselves and others that they 
could reach their goals.

\section{Academic-Related Transition Experiences}

Participants described their transition from high school to college in terms of academic experiences. Challenges were described by a few participants. These challenges included a lack of academic skills such as time management and study techniques appropriate for the college level. However, many participants described feeling well-prepared for the rigor of university coursework. For example, Gabrielle stated, "Academically, it was easy. I loved going to school. I'm kind of sad that this is my last year (laughs)."

Most participants did not express significant challenges but did note several differences observed during their transition from high school to college. For example, Mare recalled that some aspects of college academics were more difficult, while others were easier for her:

I feel like in high school it's actually harder because in college you don't have class every day, so you have time to go get the help you need before you move on. In that way it's harder but the material itself from high school is really watered down compared to the college material.

Several students appreciated the increased responsibility and structure that the college courses and curricula offered. For example, Monique felt like college classes were more focused than her high school classes:

The only difference is you don't have to worry about kids talking and screaming all over the classroom. Even though some people may not listen and may have their iPads. I actually listened because I was paying for it, so I wanted to get all the information possible. I have run into a couple incidents where I didn't understand something, and I'd go to my professor and they've always been helpful.

Other participants described their adjustment to the rigor of college coursework and the expectations of college professors. Leata described her experiences meeting the demands of college-level course work:

It was harder because in high school, I was the person that as long as I'm in class and as long as I can hear them teaching a lecture, then I'm okay and I can maneuver that way, so I didn't really study in high school. But in college (laughs) you can't do that because it's more difficult.

In general, participants were able to navigate a variety of academic-related challenges with success.

\section{Support Provided During the Transition Experience}

All participants described support they received during their transition from high school to college. Many FGCS described supportive actions taken by college personnel, including counselors, advisors, and professors. They described academic advisors who provided resources and information about college majors. Academic advisors listened to students and considered their personal backgrounds and provided them with encouragement. Joy described her relationship with her academic advisor during her freshman year as supportive:

I used to go in her office and just laugh and just have a good time. She was helping me with my classes and she was just somebody you could just come in and be like, "Let me tell you about what my sister did." She was so sweet.

Another participant, Tracy, cried as she elaborated on the specific types of support her STEM [science, technology, engineering, and mathematics] advisor provided during her transition to the university:

She did check-ins with us, like "how are classes going?” I remember one time I didn't have my books, 
she helped pay for my books. We went to financial aid together, and she got me a scholarship packet so I could stay, so she helped a lot.

Professors also appeared critical in the successful transition of some of the participants. For example, Rashed recalled the support of a professor in his major area, "He was one of my first professors and we still keep in communication today. We still set up meetings just to talk and he's a really good guy."

Participants also discussed family and community factors that aided in their transition to college. A few participants remarked that they had siblings who attended college and were helpful in offering support. Parents also were a major source of support for the first-generation students. Throughout the college journey, parents actively offered encouragement, especially during difficult times.

\section{Discussion}

The purpose of conducting this study was to explore the lived experiences of FGCS who successfully navigated the transition from high school to college. Data collected from ten participants yielded four key themes that offer insight into their experiences. The students who participated in this study described a variety of questions and concerns that emerged as they transitioned from high school to college. Despite social and familial support, participants were frequently faced with questions, confusions, and challenges similar to findings noted by Ardoin (2018) and Davis (2010). FGCS in this study reported confusion about academic policies, degree requirements, and the financial aid process. Castleman and Page (2013) reported that many FGCS have difficulty understanding how to complete these tasks and processes. Means et al. (2016) also described the uncertainty FGCS face related to financial aid and paying for college. FGCS often experience limited access to college-related information, a frequent inequity among this student population, according to Perna \& Kurban (2013). It is common for FGCS to feel overwhelmed as they transition from high school to college; these feelings often are exacerbated due to a lack of cultural and social capital (Brinkman et al., 2013).

Participants in this study experienced a range of emotions. As described by Davis (2010), FGCS often feel scared, depressed, anxious, shocked, lonely, intimidated, and homesick. Students who participated in this study also described these emotions. Participants shared that they felt isolated and lonely at the beginning of their freshman year. They reported staying in their dormitory as much as possible and being hesitant to forge relationships. However, after meeting a few peers and establishing friendships, the students began to feel more comfortable in their new setting, which is similar to findings by Demetriou et al. (2017), Frazier (2020), and Garriott and Nisle (2017). Participants maintained close ties with family while slowly expanding their social network, engaging in extracurricular activities, and building social capital. As shared by Means and Pyne (2017), FGCS described longing for a sense of belonging and immersed themselves in the college experience.

While dealing with emotional discomfort, participants in this study were optimistic and determined to persist. They were self-motivated and dedicated to graduate from college. These findings are consistent with those noted by Ricks and Warren (2020). The ability of these FGCS to persist in such an uncertain and confusing time reveals the level of perseverance and determination they possessed. Despite experiencing a host of negative emotions, participants reported that persistence led them to their senior year and to planning for ontime graduation with a bachelor's degree a few months following the interviews.

In general, participants indicated that they were prepared for the academic rigor of college. According to Draeger et al. (2015), students often describe academic rigor by the degree of course difficulty and workload and grading standards. Chaudhuri (2018) reported that FGCS expectations of course rigor often are misaligned with their actual experiences. Students expected more rigorous coursework than what they experienced, a finding consistent with the reports of participants in this study. These heightened expectations 
may stem from a lack of cultural capital and lead to feelings of anxiety or other emotions.

Solorio (2017) noted a significant positive correlation between high school course rigor and college readiness. Additionally, Warren and Goins (2019) suggested that rigorous high school coursework prepared students for the academic demands and related expectations of their first college semester. However, FGCS often attend high schools that offer less rigorous coursework. Therefore, FGCS may lack the opportunity to develop the skills and cultural capital necessary for college in the same manner as CGCS.

With the exception of a few concerns related to time-management and study-related skills, participants indicated that the transition from high school course work to college-level course work was manageable. Managing time and adhering to due dates are common examples of academic difficulties students experience upon entering college (Garriott \& Nisle, 2017). A lack of study skills can negatively impact grade point average, according to a study by Gormley et al. (2018). However, it appears that participants in this study did not allow these limitations or challenges to impact their academic performance.

FGCS in this study came from families who did not attend college but who saw the importance in education. Even though their parents had limited knowledge of college procedures and processes, they were instrumental in the participants' transition to college. Participants suggested that they shared agency with their parents; they shared similar educational goals and were jointly invested in their education (Kriegbaum et al., 2016). FGCS with greater familial support are more likely to succeed, according to Sommerfeld and Bowen (2013). Additionally, when parents share agency, students are more motivated and they are more academically successful (Kriegbaum et al., 2016).

Finally, consistent with findings from a qualitative study conducted by Gist-Mackey et al. (2018), participants in this study sought informational support from their advisors. Participants appeared to lean on their academic advisors for support on a number of issues, including financial aid. The advisors of the participants in this study appeared to embrace their role in helping FGCS successfully transition to college. Other participants reported integral relationships they shared with academic mentors such as faculty. This finding is consistent with Demetriou et al. (2017) and Frazier (2020); they described mentoring relationships originating from single course experiences and extending, in some cases, for years.

\section{Limitations to the Study}

Several limitations of this study are worth noting. First, in alignment with the nature of qualitative investigation that uses interviews, we could not verify the data provided by the participants (Hays \& Singh, 2012). Also, given the amount of time elapsed between the participants' transition from high school to college and the collection of data, the participants may have overlooked aspects of the transition. However, it is likely that noteworthy experiences and events were retained, although the degree to which they were reported is unclear. Additionally, it is important to disclose that the findings of this study lack generalizability. However, in consideration of other related studies about FGCS, these findings do offer further context for the experiences of FGCS as they transition from high school to college.

\section{Implications for Practice}

The findings of this study are valuable to school counselors, college counselors, academic support personnel, and other higher education educators. Better understanding of the lived experiences of successful FGCS can position colleges and universities to more effectively support this population of students. We aim for the implications of this study to spark consideration and innovation for preventative strategies and interventions that aim to increase the retention and graduation rates of FGCS. Specifically, we hope college administrators strive to improve the services directly provided to FGCS, expand services to the parents and schools of FGCS, 
and advocate for prospective FGCS. By offering targeted support services to this population, college professionals can influence the probability of FGCS successfully obtaining a college degree

Based on the findings of this study, we believe that colleges and universities should review their current communication practices and support services for all students, especially those for FGCS. We encourage a review of practices and services to ensure that FGCS and other students receive accurate and timely information and support relevant to their transition to college. College counselors and advisors should provide immediate support to FGCS, including outreach efforts via phone, text, and email prior to their arrival on campus to provide introductory information and establish a system of support. Additionally, it is critical for summer orientations to offer opportunities for student questions and individualized, targeted support. Orientation provides an optimal opportunity to engage parents and advance a shared agency for their child's completion of college.

Ongoing communication and support should extend beyond summer orientation and initial transition, not waiting until students demonstrate they are positioned to successfully navigate the demands of college by themselves. FGCS may benefit from additional support from academic advisors and support coaches during the first semester. As such, it is important that universities consider providing advisors who work with FGCS with reduced workloads in order to provide a higher level of targeted support. For example, upon students' arrival to campus, student affairs educators are encouraged to conduct introductory meetings with students, routinely meet with them, and provide supportive programming to this population.

During the initial meetings, educators should get to know the student's pre-college characteristics and screen for adjustment distress and non-cognitive skills (Warren \& Hale, 2016) by asking direct questions about the students' emotions and transition experiences. Advisors should discuss the best method of communication with each student. In addition, college advisors should help FGCS review the extracurricular organizations on campus and seek membership in groups of interest. By intervening early, students who are showing signs of distress can be referred to the mental health counseling center in a timely manner. Regular check-ins can help to ensure students have a thorough understanding of degree requirements, access to academic and health services, and spring semester course registration procedures. Advisors should not assume that students will receive, read, or understand information that is posted online or mass distributed. Student affairs professionals can ask questions to determine how the student is adjusting and what additional resources may be needed and make appropriate referrals as needed. Additionally, during the initial stages of the first year, advisors may want to assign first-generation students as peer supporters. By being involved in a safe process for developing social networks, students will be less likely to isolate themselves. Through direct contact, student affairs professionals can ensure that FGCS are fully supported and establish the requisite cultural and social capital for college success.

Given the role campus engagement and the development of assets play in the success of FGCS, student affairs offices are encouraged to establish meet-ups, gatherings, or events specifically designed to support these students. Incentivized programming such as psychoeducational workshops and seminars can offer targeted support to aid FGCS in navigating issues such as financial struggles, work-school balance, study skills, coping skills, and course requirements for various degrees. Furthermore, the delivery of parental workshops or meetings can prove invaluable due to the importance of family and shared agency in FGCS success. Parents who did not attend college often have many questions about how to help their child succeed in college. It is important to let parents know that they are very influential in their child's life.

Finally, student affairs offices are encouraged to establish partnerships with local school systems and high school counselors, specifically. Innovation is key in these partnerships; a key focus is to promote cultural and social capital and other assets necessary for FGCS to successfully transition to college. Student affairs professionals are positioned to help FGCS persist. By understanding personal characteristics, including strengths and challenges, student affairs professionals can respond to the specific needs of FGCS. 


\section{Future Research}

Based on the findings of this study, researchers are encouraged to further explore the positive assets FGCS possess and how they develop these characteristics. Additional qualitative investigations that yield data via observation and focus groups also may be helpful. Also, gaining additional insights into the experiences of successful FGCS from various backgrounds, including race, ethnicities, and geographical location, is warranted. Continued investigation of this student population may help expand the general knowledge base of FGCS assets and challenges. Furthermore, researchers are encouraged to explore prevention and intervention programs that build social and cultural capital early in a students' college career so they are more likely to persist when faced with challenges. For example, researchers can develop and employ longitudinal research designs that have the capacity to track students to yield valuable outcome data. Results of this targeted research can inform the services and programs student affairs professionals offer FGCS.

\section{Conclusion}

Research on successful FGCS is sparse; most of the literature outlines reasons for lower college acceptance rates, higher first-to-second-year attrition rates, and overall lower college graduation rates for this population of students. The findings of this study, however, offer insights into the experiences of successful FGCS during their transition to college. While the results confirm some of the existing research on FGCS in terms of obstacles, this study provides a new perspective on personal attributes possessed by the often-unheard voices of those students who achieved college success. College access professionals, school counselors, student affairs offices and personnel are encouraged to consider these findings and implications as they strive to support FGCS through targeted prevention and intervention that increase persistence and on-time graduation rates. 


\section{References}

Ardoin, S. (2018). College aspiration and access in working-class rural communities: The mixed signals, challenges, and new language first-generation students encounter. Lexington Books.

Atherton, M.C. (2014). Academic preparedness of first-generation college students: Different perspectives. Journal of College Student Development, 55(8), 824-829. https:/doi.org/10.1353/csd.2014.0081

Baxter Magolda, M. B. (1992). Knowing and reasoning in college: Gender related patterns in intellectual development. Jossey-Bass.

Bourdieu, P. (1977). Outline of a theory of practice. Cambridge University Press.

Bourdieu, P. (1992). Thinking about limits. Theory, Culture \& Society 9(1), 41-43. https:/doi.org/10.1177/026327692009001003

Brinkman, S., Gibson, K., \& Presnell, J. (2013, April 10-13). When the helicopters are silent: The information seeking strategies of first-generation college students. [Paper Presentation] Association of College and Research Libraries Conference, Indianapolis, IN, United States. http://hdl.handle.net/2374.MIA/5202

Bui, K. V. T. (2002). First-generation college students at a four-year university: Background characteristics, reasons for pursuing higher education, and first-year experiences. College Student Journal, 36(1), 3-11.

Castleman, B. L., \& Page, L. C. (2013). The not-so-lazy days of summer: Experimental interventions to increase college entry among low-income high school graduates. New Directions for Youth Development, 140, 77-97. https:/doi.org/10.1002/yd.20079

Chaudhuri, S. (2018). Understanding first-year college students' perception of academic rigor and help-seeking behavior in college using BCSSE and NSSE. [Unpublished doctoral dissertation]. Auburn University.

Choy, S. P. (2001). Findings from the condition of education, 2001. Institute of Education Sciences.

Creswell, J. W. \& Poth, C. N. (2017). Qualitative inquiry and research design: Choosing among five approaches (4th ed.). Sage.

Davis, J. (2010). The first generation student experience: Implications for campus practice. and strategies for improving persistence and success. Stylus Publishing.

Demetriou, C., Meece, J., Eaker-Rich, D., \& Powell, C. (2017). The activities, roles, and relationships of successful first-generation college students. Journal of College Student Development, 58(1), 19-36. https:/doi.org/10.1353/csd.2017.0001

Draeger, J., del Prado Hill, P. \& Mahler, R. (2015). Developing a student conception of academic rigor. Innovative Higher Education 40, 215-228. https://doi.org/10.1007/s10755-014-9308-1

Dumais, S. A., \& Ward, A. (2010). Cultural capital and first-generation college success. Poetics, 38(3), 245265. https://doi.org/10.1016/j.poetic.2009.11.011

Falcon, L. (2015). Breaking down barriers: First-generation college students and college success. Innovation Showcase, 10(6). https://www.league.org/innovation-showcase/breaking-down-barriers-firstgeneration-college-students-and-college-success

Forrest Cataldi, E., Bennett, C. T., \& Chen, X. (2018). First-generation students: College access, persistence, and postbachelor's outcomes. National Center for Education Statistics. https://nces.ed.gov/pubs2018/2018421.pdf

Frazier, T. (2020). The voices of African American female first-generation college student seniors at historically black colleges and universities. [Unpublished doctoral dissertation]. Brandman University.

Garriott, P. O., \& Nisle, S. (2017). Stress, coping, and perceived academic goal progress in first-generation 
college students: The role of institutional supports. Journal of Diversity in Higher Education, 11(4), 436-450. https://doi.org/10.1037/dheo0o0068

Garrison, N. J., \& Gardner, D. G. (2012, November 15). Assets first generation college students bring to the higher education setting. [Paper Presentation] Association for the Study of Higher Education, Las Vegas, NV, United States. https://files.eric.ed.gov/fulltext/ED539775.pdf

Gist-Mackey, A. N., Wiley, M. L., \& Erba, J. (2018). "You're doing great. Keep doing what you're doing”: socially supportive communication during first-generation college students' socialization. Communication Education, 67(1), 52-72. https://doi.org/10.1080/03634523.2017.1390590

Gormley, M. J., Pinho, T., Pollack, B., Puzino, K., Franklin, M. K., Busch, C., DuPaul, G. J., Weyandt, L. L., \& Anastopoulos, A. D. (2018). Impact of study skills and parent education on first-year GPA among college students with and without ADHD: A moderated mediation model. Journal of Attention Disorders, 22(4), 334-348. https://doi.org/10.1177/1087054715594422

Hays, D. G. \& Singh, A. A. (2012). Qualitative inquiry in clinical and educational settings. Guilford Press.

Horn, L., \& Nevill, S. (2006). Profile of undergraduates in U.S. postsecondary education institutions: 20032004. National Center for Education Statistics. https://nces.ed.gov/pubs2006/2006184a rev.pdf

Inman, P., \& Pascarella, E. (1998). The impact of college residence on development of critical thinking skills in college freshmen. Journal of College Student Development, 39(6), 557-568.

Kriegbaum, K., Villarreal, B., Wu, V. C., \& Heckhausen, J. (2016). Parents still matter: Patterns of shared agency with parents predict college students' academic motivation and achievement. Motivation Science, 2(2), 97-115. https://doi.org/10.1037/motooo0033

McDonough, P. M. (1997). Choosing colleges: How social class and schools structure opportunity. SUNY Press.

Means, D. R., Clayton, A. B., Conzelmann, J. G., Baynes, P., \& Umbach, P. D. (2016). Bounded aspirations: Rural, African American high school students and college access. The Review of Higher Education, $39(4), 543-569$.

Means, D. R., \& Pyne, K. B. (2017). Finding my way: Perceptions of institutional support and belonging in low-income, first-generation, first-year college students. Journal of College Student Development 58(6), 907-924. https://doi.org/10.1353/csd.2017.0071

Miles, M. B., Huberman, A. M., \& Saldana, J. (2014). Qualitative data analysis: A methods sourcebook (2nd ed.). Sage Publications.

Pascarella, E., Pierson, C., Wolniak, G., \& Terenzini, P. (2004). First-generation college students. Journal of Higher Education, 75(3), 249-284. https://doi.org/10.1353/jhe.2004.0016

Perna, L. W., \& Kurban, E. R. (2013). Improving college access and choice. In L. W. Perna \& A. Jones (Eds.). The state of college access and completion: Improving college success for students from underrepresented groups (pp. 22-45). Routledge.

Pike, G., \& Kuh, G. (2005). First- and second-generation college students: A comparison of their engagement and intellectual development. Journal of Higher Education, 76(3), 276-300. https://doi.org/10.1353/jhe.2005.0021

Redford, J., \& Mulvaney Hoyer, K. (2017). First-generation and continuing-generation college students: A comparison of high school and postsecondary experiences. National Center for Education Statistics. https://nces.ed.gov/pubs2018/2018009.pdf

Ricks, J. R., \& Warren, J. M. (2020). The experiences of successful first-generation college students with college access. [Manuscript submitted for publication]. Department of Counseling, University of North Carolina at Pembroke. 
Solorio, R. M. (2017). A quantitative study examining high school course rigor, ethnicity, and college readiness [Unpublished doctoral dissertation] Grand Canyon University.

Sommerfeld, A. K., \& Bowen, P. (2013). Fostering social and cultural capital in urban youth: A programmatic approach to promoting college success. Journal of Education, 193(1), 47-55. https://doi.org/10.1177/002205741319300106

Stanton-Salazar, R. D. (1997). A social capital framework for understanding the socialization of racial minority children and youths. Harvard Educational Review, 67(1), 1-41. https://doi.org/10.17763/haer.67.1.140676g74018u73k

Stanton-Salazar, R. D. (2001). Manufacturing hope and despair: The school and kin support networks of U.S. Mexican youth. Teachers College Press.

Thrasher, N. C. (2016). The resilience of first-generation African-American graduates from a historically black college: A phenomenological study [Unpublished doctoral dissertation]. Liberty University.

Warren, J. M., \& Goins, C. (2019). Exploring the relationships between high school course enrollment, achievement, and first semester college GPA. Journal of Educational Research and Practice, 9(1), 386-399. https://doi.org/10.5590/JERAP.2019.09.1.27

Warren, J. M., \& Hale, R. (2016). Fostering non-cognitive development of underrepresented students through rational emotive behavior therapy: Recommendations for school counselor practice. The Professional Counselor 6(1), 89-106. https://tpcjournal.nbcc.org/fostering-non-cognitive-development-ofunderrepresented-students-through-rational-emotive-behavior-therapy-recommendations-forschool-counselor-practice/

Warren, J. M., Oxendine, J. L., \& Ricks, J. R. (2020). High school to college transition: The summer melt experience. [Manuscript submitted for publication]. Department of Counseling, University of North Carolina at Pembroke.

Whitley, S. E., Benson, G., \& Wesaw, A. (2018). First generation student success: A landscape analysis of programs and services at four-year institutions. National Association of Student Personnel Administrators. https://firstgen.naspa.org/2018-landscape-analysis

Whitt, E., Edison, M., Pascarella, E., Terenzini, P., \& Nora A. (2001). Influence on students' openness to diversity and challenge in the second and third years of college. Journal of Higher Education, 72(2), 172-204. https://doi.org/10.2307/2649321

Wimberly, G. L., \& Noeth, R. J. (2004). Schools involving parents in early postsecondary planning: ACT policy report. (No. 1). ACT.

Zeisman, G. S. (2012). First-generation student success after academic warning: An exploratory analysis of academic integration, personal adjustment, family and social adjustment and psychological factors (Paper 619) [Unpublished doctoral dissertation]. Portland State University.

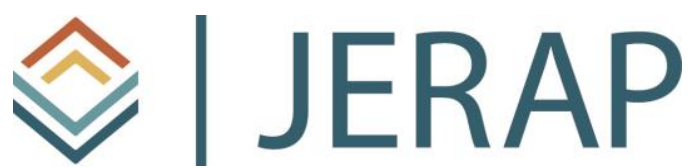

The Journal of Educational Research and Practice is a peerreviewed journal that provides a forum for studies and dialogue about developments and change in the field of education and learning. The journal includes research and related content that examine current relevant educational issues and processes. The aim is to provide readers with knowledge and with strategies to use that knowledge in educational or learning environments. JERAP focuses on education at all levels and in any setting, and includes peer-reviewed research reports, commentaries, book reviews, interviews of prominent individuals, and reports about educational practice. The journal is sponsored by the Richard W. Riley College of Education and Leadership at Walden University, and publication in JERAP is always free to authors and readers. 